\title{
An open label, multi-center, non-interventional study of the safety of Nebivolol (Nebilet) in the treatment of hypertension in Filipino adult patients: A post marketing surveillance study
}

\author{
Fatima R Collado ${ }^{1,2 *}$ \\ ${ }^{1}$ St. Luke's Medical Center, 279 E Rodriguez Sr. Ave, Quezon City, 1112 Metro Manila, Philippines \\ ${ }^{2}$ Philippine Heart Center, East Ave, Diliman, Quezon City, Metro Manila, Philippines
}

\begin{abstract}
Background: Nebivolol is a potent third generation beta-blocking agent indicated for the treatment of hypertension and is distinguished from other beta blockers by its dual mechanism of action involving high $\beta-1$ cardioselectivity and unique nitric-oxide (NO) induced vasodilation. This study aims to evaluate the safety and efficacy of Nebivolol (Nebilet) $5 \mathrm{mg}$ in the treatment of hypertension among Filipino adult patients.

Methods: This is a prospective, open-label, non-interventional study which evaluated the safety of Nebivolol (Nebilet) 5 mg in Filipino adult subjects with hypertension, aged 21 to 80 years, in an out-patient setting.

Results: A total of 1,154 patients were recruited into the study, 36 (3\%) of whom had reported adverse events (AEs). Majority of the AEs were due to headaches $(18 \%)$ and other non-specified events (32\%). Most of the adverse events reported were mild to moderate and some were known effects of $\beta$ - blockers. There were no serious or unsuspected adverse events described during the study. In terms of efficacy, nebivolol reduced blood pressure to less than $140 / 90 \mathrm{mmHg}$ or a decrease of $>10 \mathrm{~mm}$ $\mathrm{Hg}$ diastolic blood pressure (DBP) in $82 \%$ of subjects in the first follow-up visit. At the end of the treatment period, $97 \%$ had achieved target blood pressure levels.
\end{abstract}

Conclusions: The study has shown that nebivolol is a safe and effective medication for hypertensive Filipino adult patients.

\section{Introduction}

Beta-blocking agents often differ with regards to their selectivity for receptors, lipophilicity, duration of action and intrinsic sympathomimetic activity. Presently, newer beta-blockers were developed to have vasodilating effects which may be regulated by different pathways and they have improved safety and tolerability as well as lesser adverse events as compared to conventional beta-blockers [1].

Nebivolol is a potent cardio-selective beta-blocking agent indicated for the treatment of hypertension, which is distinguished from other selective beta-1-adrenergic antagonists by its peculiar hemodynamic profile. It promotes arterial and venous vasodilation that is not related to its action as a beta 1-adrenoceptor blocker. Nebivolol is indicated for the treatment of essential hypertension and for stable mild to moderate chronic heart failure in addition to standard therapies in elderly patients $>70$ years.

The pharmacology of Nebivolol has been summarized in several publications and reviews. The peculiar combination of the cardioselective ( $ß 1$-selective) $ß$-blocking properties with the restoration of NO activity and consequent reversal of endothelial dysfunction has also been demonstrated in most recently published clinical studies in hypertensive patients. In particular, Nebivolol was shown to induce a systematic hemodynamic response, consisting of preservation of cardiac output, reduction of peripheral resistance, and improved diastolic dysfunction. This pattern has favorable implications not only in the treatment of hypertension but also in the treatment of heart failure, one of the major complications of hypertension.

Nebivolol is a third-generation $\beta$-blocker, combining selective $\beta 1$ adrenergic receptor blockade with a vasodilatory property mediated by the L-arginine/ NO pathway. Nebivolol hydrochloride is the racemate of two enantiomers: d-nebivolol (SRRR-nebivolol) and l-nebivolol (RSSS-nebivolol). The mixture (1:1) of the two enantiomers is named dl-nebivolol. The two enantiomers have different pharmacological activities: $d$-nebivolol is responsible for the selective $\beta 1$-antagonism, while l-nebivolol is involved in the endothelial/NO-dependent vasodilation. Chemically nebivolol is (RSSS+SRRR) - [iminobis (methylene)] bis [6- fluoro-3,4-2H-1-benzopyran-2-methanol] hydrochloride [1-3]. Nebivolol is a lipophilic drug, with an ionisation constant $(\mathrm{pKa})$ of 8.2 and a partition co-efficient octanol/water of 1.4

${ }^{\star}$ Correspondence to: Fatima R Collado, St. Luke’s Medical Center, 279 E Rodriguez Sr. Ave, Quezon City, 1112 Metro Manila, Philippines, Philippine Heart Center, East Ave, Diliman, Quezon City, Metro Manila, Philippines, E-mail: ecolladofatima@gmail.com

Key words: nebivolol, nebilet, hypertension, vasodilator, beta-blocker, betablocking, beta-antagonist, d-nebivolol, l-nebivolol, "itric oxide, no, safety, pms, post marketing surveillance, phase iv

Received: April 30, 2018; Accepted: May 16, 2018; Published: May 21, 2018 
Collado FR (2018) An open label, multi-center, non-interventional study of the safety of Nebivolol (Nebilet) in the treatment of hypertension in Filipino adult patients: A post marketing surveillance study

Nebivolol is structurally different from conventional $\beta$-blocking drugs, which are usually modelled on naturally $\beta$-adrenergic agonists such as adrenaline and noradrenaline.

Nebivolol has a dual mechanism of action. It has $\beta$-receptor activity, which means that it is a highly selective $\beta 1$-receptor antagonist and a $\beta 3$-receptor agonist. It also stimulates nitric oxide release; this property is responsible for the vasodilatory, antioxidant, antiproliferative and antiplatelet actions of the drug.

The haemodynamic profiles of nebivolol and atenolol appear to be completely different. The response to atenolol is typical of $\beta 1$-blockers, with evidence of reduced cardiac output and increased peripheral vascular resistance, whereas that of nebivolol is characterized by a decrease in systemic vascular resistance and an improvement in left ventricular performance, partly secondary to an improvement in diastolic function. These observations were confirmed in two studies comparing the hemodynamic effects of nebivolol and atenolol in healthy subjects $[2,3]$. In both of these studies nebivolol significantly increased left ventricular ejection fraction (LVEF), stroke volume, cardiac output and end-diastolic volume, while end-systolic volume remained unchanged. Atenolol, on the other hand, significantly decreased LVEF and cardiac output; stroke volume and end-diastolic volume remained unchanged, while the end-systolic volume increased significantly. Peripheral vascular resistance was significantly reduced by nebivolol and increased by atenolol. The analysis of diastolic function showed that the peak filling rate was improved by nebivolol and decreased by atenolol.

Nebivolol has also been found to have favourable haemodynamic characteristics in hypertensive patients in studies using systolic time intervals [1] or radionuclide ventriculography [4]. The results of these studies showed that nebivolol improves left ventricular function by increasing stroke volume, LVEF and diastolic compliance and reducing systemic vascular resistance. Nebivolol seems to maintain a better haemodynamic profile in hypertensive patients when compared to other beta-blockers. In a double-blind crossover trial, the systemic vascular resistance index fell during nebivolol treatment (7.5\%) but did not change during bisoprolol treatment [5] while the cardiac index decreased significantly during bisoprolol treatment (10\%) but did not change in the period of nebivolol administration.

In a double-blind parallel group study, nebivolol increased stroke volume, cardiac output and ejection fraction and decreased peripheral vascular resistance, whereas atenolol exerted opposite effects on these haemodynamic parameters [6]. Morever, only nebivolol improved diastolic function by increasing left ventricular compliance. In recent years, understanding of the role of the coronary microcirculation in human arterial hypertension has improved substantially because coronary flow reserve of the left anterior descending artery can now be assessed by trans-oesophageal or transthoracic Doppler echocardiography [7-15].

Coronary flow reserve (CFR) is the difference between coronary blood flow at rest and after maximal vasodilatation induced by the administration of a vasodilator (for example, adenosine or dipyridamole). It is usually expressed as the ratio of maximal (hyperaemic) to resting coronary blood flow. CFR is impaired in hypertensive patients as a consequence of increased afterload, left ventricular hypertrophy, vascular hypertrophy, endothelial dysfunction and extravascular compression related to diastolic dysfunction. In a study performed in newly diagnosed grade I-II hypertensive patients, nebivolol induced an absolute increase of $8 \%$ or more in coronary flow reserve in nine of the 14 patients investigated (64.3\%). This study showed that nebivolol preserves coronary flow at rest and increases hyperaemic flow velocities despite the reduction of metabolic ( $\mathrm{O} 2$ consumption) and haemodynamic (diastolic blood pressure) determinants. The increase of hyperaemic coronary flow velocities appeared to be due to the reduction of coronary resistance [16].

The favourable haemodynamic profile of nebivolol is of potential advantage for hypertensive patients, whose left ventricular compliance is often impaired, even before overt evidence of left ventricular hypertrophy (LVH). Nebivolol has been studied in both animals and patients with LVH. This drug reduces diastolic and systolic blood pressures and LVH in hypertensive patients [17]. This is an important aspect since the reduction of LVH improves the prognosis of hypertensive patients and reduces the incidence of cardiovascular events. In a recent experimental study it was shown, in spontaneously hypertensive rats, that the antihypertensive effect of nebivolol was accompanied by important reductions of LVH and collagen deposition in both vascular and left ventricle tissue, and these changes were maintained for a long period after therapy withdrawal [18]. Enhancement of arterial relaxation, reduction of LVH and prevention of collagen accumulation could reduce ventricular and vascular stiffness and improve cardiovascular function. These experimental results support the clinical usefulness of nebivolol in hypertension.

Dose-finding studies established that $5 \mathrm{mg}$ of nebivolol is the most appropriate dose for antihypertensive treatment [19-21]. The troughto-peak ratio of nebivolol is 0.90 [21], demonstrating that most of the hypotensive effect is still present 24 hours after a dose. The value of the trough-to-peak ratio for an antihypertensive drug should be $>0.50$ to justify once-a-day administration. The peak-to-trough ratio of nebivolol was recently compared directly with that of bisoprolol and carvedilol in a randomised, double-blind, placebo controlled, crossover trial in 16 healthy males. Subjects received $10 \mathrm{mg}$ bisoprolol or $50 \mathrm{mg}$ carvedilol or $10 \mathrm{mg}$ nebivolol or placebo on the first morning of each experimental period, followed by $5 \mathrm{mg}$ bisoprolol once daily or 25 $\mathrm{mg}$ carvedilol twice daily or $5 \mathrm{mg}$ nebivolol once daily or placebo for 1 week. The heart rate trough-to-peak ratios (expressed as percentages) in the long-term were as follows: bisoprolol 58\%; carvedilol 85\%; nebivolol 91\% [22]. The blood pressure lowering effect of nebivolol follows the circadian rhythm of blood pressure as monitored by ambulatory blood pressure measurements [23,24].

Randomised, double-blind, placebo-controlled trials have established the efficacy and tolerability of nebivolol in patients with mild to moderate essential hypertension [20,21,25-27]. In these evaluations, Nebivolol was administered in single daily doses of 1 to 10 $\mathrm{mg} /$ day for 4 to 12 weeks. These studies included a variable number of patients aged 18 to 71 years.

Doses of nebivolol $>5 \mathrm{mg}$ reduced systolic and diastolic blood pressures to a greater extent than placebo. These placebo-controlled studies showed that the percentage of responders (defined as patients achieving a diastolic blood pressure $<90 \mathrm{mmHg}$ or a decrease of $>10 \mathrm{mmHg}$ ) ranged from approximately 50 to $80 \%$, depending on the treatment duration. In an open observational study [28] the antihypertensive activity of nebivolol was assessed in 3,741 patients who had been previously treated (group $A=1,656$ ) or untreated (group $\mathrm{B}=2,085$ ). After 2 weeks the percentage of responders was $52 \%$ in group $A$ and $61 \%$ in group B. These figures rose to $74 \%$ and $86 \%$, respectively, by 6 months. Similar results were found in another more recent and larger observational study (5,740 patients) [29]. Again, it 
Collado FR (2018) An open label, multi-center, non-interventional study of the safety of Nebivolol (Nebilet) in the treatment of hypertension in Filipino adult patients: A post marketing surveillance study

was found that the response rate to nebivolol rose over time. This study demonstrated the efficacy and safety of nebivolol for the treatment of mild hypertension in normal clinical practice. Blood pressure reductions with nebivolol as monotherapy or add-on therapy were very similar [29]. The conclusions of both these studies were that the antihypertensive efficacy of nebivolol continues to increase during treatment $[28,29]$.

Nebivolol has been compared with several standard antihypertensive therapies, including other beta-blockers (atenolol, metoprolol, bisoprolol) [27-33], calcium-channel blockers (amlodipine, nifedipine) [34,35], ACE-inhibitors (enalapril, lisinopril) [24,36,37] angiotensin II receptor antagonists [38] and a thiazide diuretic (hydrochlorothiazide) [25].

In the studies comparing nebivolol with other beta-blockers, both nebivolol and the comparator agent produced significant reductions in blood pressure and these reductions were similar for nebivolol and either atenolol, metoprolol or bisoprolol [27-33] In the atenolol studies, nebivolol $5 \mathrm{mg}$ once daily produced a similar reduction in blood pressure as 50 and $100 \mathrm{mg}$ of atenolol $[31,39,40]$.

Therefore, the antihypertensive efficacy of nebivolol was similar to that of other beta-blocking drugs.

Nebivolol $5 \mathrm{mg}$ once daily was similar in efficacy to amlodipine 5 or $10 \mathrm{mg}$ once daily and nifedipine $20 \mathrm{mg}$ twice a day but the percentage of patients with fully normalized blood pressure (diastolic blood pressure $<90 \mathrm{mmHg}$ ) was significantly higher with nebivolol than with nifedipine or amlodipine [24,34,35,41]. In addition, nebivolol tended to prevent increases in early morning blood pressure better than nifedipine, as assessed by 24 -hour ambulatory blood pressure measurements [42]. Furthermore, in the studies comparing nebivolol with nifedipine or amlodipine, heart rate was decreased by nebivolol and slightly increased with the two dihydropyridines: the lower heart rate is a potential advantage of nebivolol, due to the epidemiologically determined relation between heart rate and cardiovascular morbidity [37,41].

The antihypertensive effect of nebivolol $5 \mathrm{mg}$ once daily was similar to that of lisinopril $20 \mathrm{mg}$ once daily, although nebivolol appeared to achieve maximal blood pressure reduction earlier in therapy [36]. In contrast, reduction of diastolic blood pressure with nebivolol $5 \mathrm{mg} /$ daily was greater than that achieved with enalapril $10 \mathrm{mg} /$ daily $[37,43]$.

The antihypertensive efficacy of nebivolol $5 \mathrm{mg}$ once a day and losartan $50 \mathrm{mg}$ once a day was investigated in a multicenter double-blind trial in 314 patients with essential hypertension [38]. The difference between nebivolol and losartan was not statistically significant as far as the systolic blood pressure reduction was concerned, whereas nebivolol achieved a statistically significant, greater reduction of diastolic blood pressure after 3, 6 and 12 weeks of treatment, in spite of the fact that addition of hydrochlorothiazide was required in a significantly smaller proportion of subjects treated with nebivolol. The prevalence of patients with normalised blood pressure (diastolic blood pressure $<90$ $\mathrm{mmHg}$ ) was also significantly higher with nebivolol than with losartan after 6 weeks whereas after 12 weeks it was similar with both drugs. The conclusion of this study was that nebivolol has a greater effect on diastolic blood pressure than losartan.

In a recent meta-analysis [42] of 13 randomised controlled trials in which nebivolol was compared in nine studies with a variety of other antihypertensive drugs (ACE-inhibitors, other beta-blockers, angiotensin II receptor blockers, calcium-channel blockers) and in other studies with placebo, antihypertensive response rates were statistically significantly higher with nebivolol than with ACE-inhibitors and all antihypertensive drugs combined. Moreover, a higher proportion of patients receiving nebivolol had normalised blood pressure levels compared with patients receiving angiotensin II receptor blockers, calcium channel blockers and all of the antihypertensive drugs combined [44].

The primary objective of this study was to evaluate the safety of Nebivolol (Nebilet) $5 \mathrm{mg}$ in usual clinic practice when used in the treatment of hypertension in adult patients by assessing the incidence of adverse events at 2 follow-up visits (Day 14 to Day 60 after baseline visit).

The global/ overall efficacy of Nebivolol (Nebilet) $5 \mathrm{mg}$ was assessed by doctors at 2 follow-up visits based on the following parameters:

a. Blood pressure $<140 / 90 \mathrm{mmHg}$ or diastolic blood pressure reduction $>10 \mathrm{mmHg}$ compared to baseline

b. $\%$ of patients with diastolic blood pressure $<90 \mathrm{mmHg}$ at follow-up visits

c. \% of patients with systolic blood pressure $<140 \mathrm{mmHg}$ at follow-up visits

\section{Methods}

\section{Ethical conduct}

The trial was conducted following the principles set forth by the National Guidelines for Biomedical/Behavioral Research of the National Ethics Committee (NEC) of the Philippines; The Belmont Report: Ethical Principles and Guidelines for the Protection of Human Subjects of Research; World Medical Association Declaration of Helsinki regarding protection of the rights and welfare of human subjects participating in this study; applicable government regulations and institutional research policies and procedures.

\section{Study population}

The Philippine Food and Drug Administration have approved a study population of 3000 patients to be enrolled in the study within 3 years. The decision to use Nebivolol (Nebilet) $5 \mathrm{mg}$ was a joint decision made by the subject and the Investigator. The Investigator discussed product information with the subject as per usual practice.

Inclusion criteria: Filipino patients, male or female, age 21 to 80 with arterial hypertension that were treatment-naïve to Nebivolol.

Exclusion criteria: Subjects with conditions contraindicated with the use of Nebivolol (Nebilet) $5 \mathrm{mg}$ based on the approved local product label in the Philippines were excluded in this study. These conditions included:

1. Hypersensitivity to Nebivolol (Nebilet) or to any excipients in the formulation

\section{Liver insufficiency or liver function impairment.}

3. Acute heart failure, cardiogenic shock or episodes of heart failure decompensation requiring intravenous inotropic therapy

\section{Study design}

This is a prospective observational, non-interventional study which evaluated Nebivolol (Nebilet) $5 \mathrm{mg}$ in Filipino adult subjects with hypertension, 21 to 80 years of age.

The data collected was under routine clinical conditions, therefore, subjects who had any of the contraindications specified in the product package insert were excluded. Nebivolol (Nebilet) $5 \mathrm{mg}$ was prescribed 
Collado FR (2018) An open label, multi-center, non-interventional study of the safety of Nebivolol (Nebilet) in the treatment of hypertension in Filipino adult patients: A post marketing surveillance study

and administered according to the approved product information of the drug in the Philippines. A. Menarini Philippines, Inc. did not provide the drug for this study.

\section{Endpoints}

Parameters on safety: Safety of Nebivolol (Nebilet) $5 \mathrm{mg}$ was evaluated by assessing the incidence of adverse events at follow-up visits. All adverse events, whether detected by the Investigator or reported by the subject, were recorded on the case report form (CRF), with the date of occurrence, time of onset, duration, likely relationship to study medication, action taken, patient outcome and whether the event met the criteria for serious adverse events.

Parameters on efficacy: Efficacy of Nebivolol (Nebilet) $5 \mathrm{mg}$ was evaluated using the following parameters: sitting blood pressure $<140 / 90 \mathrm{mmHg}$ or diastolic blood pressure reduction $>10 \mathrm{mmHg}$ compared to baseline, $\%$ of patients with sitting diastolic blood pressure $<90 \mathrm{mmHg}$, and \% of patients with sitting systolic blood pressure $<140$ $\mathrm{mmHg}$ at follow-up visits.

\section{Efficacy and safety assessments}

The use and dosage recommendations for Nebivolol (Nebilet) $5 \mathrm{mg}$ were based on the approved local product label and were adjusted solely according to medical and therapeutic necessity. The recommended dose of Nebivolol (Nebilet) is one tablet ( $5 \mathrm{mg}$ ) daily, given preferably at the same time of the day. Tablets were to be taken with meals or upon Investigator's judgment.

The individual assessment of treatment in terms of safety and efficacy lasted up to 60 days.

Baseline visit: At baseline visit, the following information were obtained and recorded: demographic profile (name of physician, name of institution, date of visit, date of birth and sex), medical history, complete physical examination, and concomitant medications. The prescription of Nebivolol (Nebilet) was documented and the schedule for the next visit was explained.

Follow-up visits (Day 14 up to Day 60): During the follow-up visits, the following information were obtained and recorded: date of visit, study drug medication and frequency, changes in concomitant medications if any, adverse event/s, efficacy parameters and patient status at the end of the study.

Safety analysis: The safety population was defined as all patients who received at least one dose of study medication during the observation period. Safety data (Adverse Events, SAEs, premature discontinuations from the study, and concomitant medications) were summarized within the safety population in accordance with A. Menarini Philippines, Inc. SOP for safety reporting.

Baseline characteristics (demographics and medical history) were also summarized within the safety populations.

\section{Statistical analysis}

All retrieved CRFs were encoded and were included in the efficacy and safety analysis.

For continuous demographic and efficacy variables, the mean \pm standard deviation, median, minimum and maximum values were presented. For all qualitative and discrete parameters, frequencies and percentages in each class were presented. Descriptive statistics were presented at each scheduled assessment on these parameters.
To test for significance of difference of Visit 2 and Visit 3 parameters compared to baseline, $90 \%$ confidence intervals were computed and $\mathrm{p}$-values using paired t-test were presented.

Sample size determination: The Philippine Food and Drug Administration (FDA) requires that a Post Marketing Surveillance study be conducted nationwide and has approved a sample size of 3000 patients in 3 years duration for this study.

\section{Results}

\section{Study conduct, patient disposition and baseline characteristics}

A total of 1,140 CRFs were retrieved, with $18 \%$ of them less than 40 years old. $50 \%$ were between 40 and 60 years old and $3 \%$ were older than 60 . Slightly more females were enrolled at $54 \%$ and men accounting for about $45 \%$ (Tables 1-3).

About $70 \%$ had family history of hypertension and approximately the same percentage was taking concomitant medications. A small percentage, $3 \%$, had history of allergy.

About one fourth of the patients were smoking or had diabetes. Slightly more than half had hyperlipidemia. Approximately $17 \%$ were newly diagnosed hypertensives.

\section{Efficacy}

At baseline, the average systolic blood pressure was $152 \mathrm{mmHg}$ with a maximum of $240 \mathrm{mmHg}$ while the average diastolic blood pressure was $93 \mathrm{mmHg}$ with a maximum of $139 \mathrm{mmHg}$. The average heart rate was 85 beats/min with a maximum of 140 beats/min (Tables 4 and 5).

Table 1. Characteristics of study participants

\begin{tabular}{|l|l|}
\hline \multicolumn{2}{|l|}{} \\
\hline Age (years) & N $(\%)$ \\
\hline N with age data & 1,140 \\
\hline Mean + SD & $52.41+13.29$ \\
\hline Median & 52 \\
\hline Minimum & 18 \\
\hline Maximum & 93 \\
\hline Gender & \\
\hline Male & $518(44.88)$ \\
\hline Female & $618(53.55)$ \\
\hline Missing data & $18(1.56)$ \\
\hline Weight (kg) & \\
\hline N with weight data & 923 \\
\hline Mean + SD & $65.91+12.91$ \\
\hline Median & 65 \\
\hline Minimum & 35 \\
\hline Maximum & 132.9 \\
\hline
\end{tabular}

Table 2. Other relevant history and concomitant drugs

\begin{tabular}{|l|l|}
\hline \multicolumn{1}{|l|}{} & N (\%) \\
\hline With allergies & \\
\hline Yes & $40(3.47)$ \\
\hline No & $611(52.95)$ \\
\hline Missing answer & $503(43.59)$ \\
\hline With family history of hypertension & \\
\hline Yes & $787(68.20)$ \\
\hline No & $105(9.10)$ \\
\hline Missing answer & $262(22.71)$ \\
\hline With concomitant drugs & \\
\hline Yes & $822(71.23)$ \\
\hline No & $332(28.77)$ \\
\hline
\end{tabular}


Collado FR (2018) An open label, multi-center, non-interventional study of the safety of Nebivolol (Nebilet) in the treatment of hypertension in Filipino adult patients: A post marketing surveillance study

Table 3. Medical history

\begin{tabular}{|c|c|}
\hline & $\mathbf{N}(\%)$ \\
\hline \multicolumn{2}{|l|}{ Smoker } \\
\hline Yes & $336(29.12)$ \\
\hline No & $783(67.85)$ \\
\hline Missing answer & $35(3.03)$ \\
\hline \multicolumn{2}{|c|}{ Prior history of coronary artery disease } \\
\hline Yes & $148(12.82)$ \\
\hline No & $950(82.32)$ \\
\hline Missing answer & $56(4.85)$ \\
\hline \multicolumn{2}{|c|}{ Prior myocardial infarction } \\
\hline Yes & $62(5.37)$ \\
\hline No & $1043(90.38)$ \\
\hline Missing answer & $49(4.25)$ \\
\hline \multicolumn{2}{|c|}{ Prior percutaneous coronary intervention } \\
\hline Yes & $5(0.43)$ \\
\hline No & $1096(94.97)$ \\
\hline Missing answer & $53(4.59)$ \\
\hline \multicolumn{2}{|c|}{ Prior coronary artery bypass surgery } \\
\hline Yes & $8(0.69)$ \\
\hline No & $1094(94.80)$ \\
\hline Missing answer & $52(4.51)$ \\
\hline \multicolumn{2}{|c|}{ Cerebrovascular accident in the previous months } \\
\hline Yes & $34(2.95)$ \\
\hline No & $1067(92.46)$ \\
\hline Missing answer & $53(4.59)$ \\
\hline \multicolumn{2}{|l|}{ Hypertension } \\
\hline Yes & 939 (81.37) \\
\hline No & $196(16.98)$ \\
\hline Missing answer & $19(1.65)$ \\
\hline \multicolumn{2}{|l|}{ Hyperlipidaemia } \\
\hline Yes & $583(50.52)$ \\
\hline No & $523(45.32)$ \\
\hline Missing answer & $48(4.16)$ \\
\hline \multicolumn{2}{|c|}{ Atrial fibrillation } \\
\hline Yes & $36(3.12)$ \\
\hline No & $1020(88.39)$ \\
\hline Missing answer & $98(8.49)$ \\
\hline \multicolumn{2}{|l|}{ Diabetes } \\
\hline Yes & $233(20.19)$ \\
\hline No & 849 (73.57) \\
\hline Missing answer & $72(6.24)$ \\
\hline
\end{tabular}

Table 4. Descriptive statistics, blood pressure and heart rate, visits 1 to 3

\begin{tabular}{|c|c|c|c|c|}
\hline \multicolumn{5}{|c|}{ Baseline Visit } \\
\hline & N & Mean + SD & Min & Max \\
\hline SBP & 1154 & $152.75 \pm 15.93$ & 90.00 & 240.00 \\
\hline DBP & 1154 & $93.30 \pm 10.05$ & 20.00 & 139.00 \\
\hline Heart rate & 1111 & $85.86 \pm 11.62$ & 54.00 & 140.00 \\
\hline \multicolumn{5}{|c|}{ Visit 2 } \\
\hline \multicolumn{5}{|c|}{ Mean \pm SD } \\
\hline SBP & 1125 & $134.29 \pm 12.91$ & Min & Max \\
\hline DBP & 1125 & $83.36 \pm 8.64$ & 30.00 & 185.00 \\
\hline Heart rate & 1092 & $77.00 \pm 9.04$ & 50.00 & 181.00 \\
\hline \multicolumn{5}{|c|}{ Visit 3 } \\
\hline SBP & 1080 & $125.05 \pm 10.57$ & 90.00 & 160.00 \\
\hline DBP & 1080 & $78.06 \pm 7.06$ & 40.00 & 100.00 \\
\hline Heart rate & 1061 & $73.16 \pm 8.10$ & 48.00 & 112.00 \\
\hline
\end{tabular}

Table 5. Efficacy results

\begin{tabular}{|l|c|c|}
\hline & Visit 2 N (\%) & Visit 3 N (\%) \\
\hline $\begin{array}{l}\mathrm{BP} \leq 140 / 90 \text { or diastolic blood pressure reduction } \\
>10 \mathrm{mmHg} \text { from baseline }\end{array}$ & $921(81.87)$ & $1049(97.13)$ \\
\hline$\%$ of patients w/ diastolic $\mathrm{bp} \leq 90 \mathrm{mmHg}$ & $1063(94.49)$ & $1078(99.81)$ \\
\hline$\%$ of patients $\mathrm{w} /$ systolic $\mathrm{bp} \leq 140 \mathrm{mmHg}$ & $944(83.91)$ & $1050(97.22)$ \\
\hline
\end{tabular}

At Visit 2, 82\% had blood pressures below 140/90 mmHg or had a reduction of more than $10 \mathrm{mmHg}$ in diastolic blood pressure. About $95 \%$ had diastolic blood pressure below $90 \mathrm{mmHg}$ and $84 \%$ had systolic blood pressure less than $140 \mathrm{mmHg}$.

At Visit 3, 97\% had blood pressures below 140/90 $\mathrm{mmHg}$ or had a reduction of more than $10 \mathrm{mmHg}$ in diastolic blood pressure. About 99\% had diastolic blood pressure below $90 \mathrm{mmHg}$ and $97 \%$ had systolic blood pressure less than $140 \mathrm{mmHg}$ (Tables 6 and 7).

The reduction in systolic and diastolic blood pressures and heart rate were significant with p-values less than 0.0001 and there were further reductions in all three parameters in Visit 3.

\section{Safety}

Only 36 patients (3\%) developed adverse events during the treatment period. This is consistent with data in the approved product label (Tables 8 and 9).

Most of the adverse events reported were mild to moderate and some were known effects of therapy (Tables 10 and 11).

Out of the 44 reported adverse events, only 4 led to treatment discontinuation (bradycardia, dizziness, palpitations and 1 unspecified reason). In 9 patients, dose was reduced while in majority of patients, treatment was continued with no changes (Table 12).

About $80 \%$ of the adverse events resolved or improved with time, and about $6 \%$ was unchanged during the treatment period while outcome in $14 \%$ was not reported. It should be noted that only $7 \%$ and $16 \%$ were classified as definite and probable consequences of nebivolol therapy (Tables 13 and 14) (Figures 1-3).

\section{Discussion}

Beta- blockers are one of the oldest classes of anti-hypertensive drugs in the market. In recent years, newer, safer and more effective $\beta$ - blockers have emerged. Nebivolol, a $3^{\text {rd }}$ generation $\beta$-receptor antagonist, is the most recent of its class and possesses a dual mechanism of action with the highest cardioselectivity as well as a NO inducedvasodilatory effect on the vascular endothelium. Safety and tolerability have always been a concern for traditional $\beta$-blockers with issues such as bradycardia, erectile dysfunction, impaired glucose tolerance as well as worsening of bronchospasm in predisposed patients.

This study focused on the safety and tolerability of nebivolol in hypertensive patients in a real-world setting. The results showed that only $3 \%$ of patients experienced adverse events in the intention to treat

Table 6. Mean reduction in blood pressure $(\mathrm{mmHg})$ and heart rate $(/ \mathrm{min})$

\begin{tabular}{|c|c|c|c|c|}
\hline \multicolumn{5}{|c|}{ Baseline to Visit 2} \\
\hline & $\mathbf{N}$ & Mean \pm SD & $\begin{array}{c}90 \% \\
\text { Confidence } \\
\text { Limits for } \\
\text { Mean }\end{array}$ & p-value* \\
\hline SBP & 1125 & $18.79 \pm 13.20$ & $(18.14,19.44)$ & $<0.0001$ \\
\hline DBP & 1125 & $10.05 \pm 10.41$ & $(9.54,10.56)$ & $<0.0001$ \\
\hline HR & 1092 & $9.01 \pm 8.61$ & $(8.58,9.44)$ & $<0.0001$ \\
\hline \multicolumn{5}{|c|}{ *Used paired t-test } \\
\hline \multicolumn{5}{|c|}{ Baseline to Visit 3} \\
\hline & $\mathbf{N}$ & Mean \pm SD & $\begin{array}{c}90 \% \\
\text { Confidence } \\
\text { Limits for } \\
\text { Mean }\end{array}$ & p-value* \\
\hline SBP & 1080 & $28.25 \pm 14.90$ & $(27.50,28.99)$ & $<0.0001$ \\
\hline DBP & 1080 & $15.45 \pm 10.45$ & $(14.92,15.97)$ & $<0.0001$ \\
\hline HR & 1061 & $12.88 \pm 10.56$ & $(12.35,13.41)$ & $<0.0001$ \\
\hline \multicolumn{5}{|c|}{ *Used paired t-test } \\
\hline
\end{tabular}


Collado FR (2018) An open label, multi-center, non-interventional study of the safety of Nebivolol (Nebilet) in the treatment of hypertension in Filipino adult patients: A post marketing surveillance study

Table 7. Mean percent reduction (\%) in blood pressure and heart rate

\begin{tabular}{|c|c|c|c|}
\hline \multicolumn{5}{|c|}{ Baseline to Visit 2 } \\
\hline & $\mathbf{N}$ & Mean \pm SD & $\mathbf{9 0 \%}$ Confidence Limits for Mean \\
\hline SBP & 1125 & $11.86 \pm 7.86$ & $(11.48,12.25)$ \\
\hline DBP & 1125 & $10.04 \pm 10.98$ & $(9.50,10.98)$ \\
\hline HR & 1092 & $9.83 \pm 8.86$ & $(9.39,10.27)$ \\
\hline \multicolumn{3}{|c|}{ Baseline to Visit 3 } \\
\hline \multicolumn{5}{|c|}{ MBP } & 1080 & $17.86 \pm 8.35$ & $(17.44,18.28)$ \\
\hline DBP & 1080 & $15.67 \pm 10.97$ & $(15.12,16.22)$ \\
\hline HR & 1061 & $14.05 \pm 10.51$ & $(13.52,14.58)$ \\
\hline
\end{tabular}

Table 8. Number of participants with and without AEs

\begin{tabular}{|c|c|}
\hline & $\mathbf{N}(\mathbf{\%})$ \\
\hline With AE & $36(3.12)$ \\
\hline Without AE & $1,118(96.88)$ \\
\hline Total & $\mathbf{1 , 1 5 4}(\mathbf{1 0 0 . 0 0 )}$ \\
\hline
\end{tabular}

Table 9. Number of AEs

\begin{tabular}{|l|l|}
\hline Adverse event & N (\%) \\
\hline Bradycardia & $2(4.55)$ \\
\hline Chest Pains & $2(4.55)$ \\
\hline Dizziness & $2(4.55)$ \\
\hline DOB & $3(6.82)$ \\
\hline Dry mouth & $3(6.82)$ \\
\hline Easy Fatigability & $1(2.27)$ \\
\hline Erectile Dysfunction & $1(2.27)$ \\
\hline Headache & $8(18.18)$ \\
\hline Hyperacusis & $1(2.27)$ \\
\hline Muscle pain & $1(2.27)$ \\
\hline Nape Pains & $1(2.27)$ \\
\hline Nausea & $1(2.27)$ \\
\hline Palpitations & $2(4.55)$ \\
\hline Temporal headache & $1(2.27)$ \\
\hline Tingling sensation & $1(2.27)$ \\
\hline Not specified & $14(31.82)$ \\
\hline Total & $44(100.00)$ \\
\hline
\end{tabular}

Table 10. Number of AEs by severity

\begin{tabular}{|c|c|c|c|}
\hline \multirow{2}{*}{ Adverse event } & \multicolumn{2}{|c|}{ Severity } & \multirow{2}{*}{ Total } \\
\cline { 2 - 4 } & Mild & Moderate & 2 \\
\hline Bradycardia & 2 & 0 & 2 \\
\hline Chest Pains & 0 & 2 & 2 \\
\hline Dizziness & 0 & 1 & 3 \\
\hline DOB & 2 & 3 & 3 \\
\hline Dry mouth & 0 & 1 & 1 \\
\hline Easy Fatigability & 0 & 0 & 1 \\
\hline Erectile Dysfunction & 1 & 2 & 8 \\
\hline Headache & 6 & 1 & 1 \\
\hline Hyperacusis & 0 & 1 & 1 \\
\hline Muscle pain & 0 & 0 & 1 \\
\hline Nape Pains & 1 & 0 & 2 \\
\hline Nausea & 1 & 1 & 1 \\
\hline Palpitations & 1 & 0 & 1 \\
\hline Temporal headache & 1 & 0 & 14 \\
\hline Tingling sensation & 1 & $\mathbf{4 9}$ & $\mathbf{4 4}$ \\
\hline Not specified & 9 & & \\
\hline Total & $\mathbf{2 5}$ & & 19 \\
\hline & & & \\
\hline & & & \\
\hline
\end{tabular}

Table 11. Number of AEs by treatment

\begin{tabular}{|l|c|c|c|c|c|}
\hline \multirow{2}{*}{ Adverse event } & \multicolumn{4}{|c|}{ Treatment } & \multirow{2}{*}{ Total } \\
\cline { 2 - 5 } & Continued & Reduced & Stopped & $\begin{array}{c}\text { Missing } \\
\text { Answer }\end{array}$ & \\
\hline Bradycardia & 1 & 0 & 1 & 0 & 2 \\
\hline Chest Pains & 0 & 2 & 0 & 0 & 2 \\
\hline Dizziness & 1 & 0 & 1 & 0 & 2 \\
\hline DOB & 1 & 2 & 0 & 0 & 3 \\
\hline Dry mouth & 3 & 0 & 0 & 0 & 3 \\
\hline Easy Fatigability & 1 & 0 & 0 & 0 & 1 \\
\hline Erectile Dysfunction & 1 & 0 & 0 & 0 & 1 \\
\hline Headache & 5 & 3 & 0 & 0 & 8 \\
\hline Hyperacusis & 0 & 1 & 0 & 0 & 1 \\
\hline Muscle pain & 1 & 0 & 0 & 0 & 1 \\
\hline Nape Pains & 1 & 0 & 0 & 0 & 1 \\
\hline Nausea & 1 & 0 & 0 & 0 & 1 \\
\hline Palpitations & 1 & 0 & 1 & 0 & 2 \\
\hline Temporal headache & 1 & 0 & 0 & 0 & 1 \\
\hline Tingling sensation & 1 & 0 & 0 & 0 & 1 \\
\hline Not specified & 11 & 1 & 1 & 1 & 14 \\
\hline Total & $\mathbf{3 0}$ & $\mathbf{9}$ & $\mathbf{4}$ & $\mathbf{1}$ & $\mathbf{4 4}$ \\
\hline
\end{tabular}

Table 12. Number of AEs by outcome

\begin{tabular}{|l|c|c|c|c|c|}
\hline \multirow{2}{*}{ Adverse event } & \multicolumn{5}{|c|}{ Outcome } \\
\cline { 2 - 5 } & Disappeared & Improved & Unchanged & $\begin{array}{c}\text { Missing } \\
\text { answer }\end{array}$ & Total \\
\hline Bradycardia & 1 & 0 & 0 & 1 & 2 \\
\hline Chest Pains & 1 & 1 & 0 & 0 & 2 \\
\hline Dizziness & 2 & 0 & 0 & 0 & 2 \\
\hline DOB & 1 & 2 & 0 & 0 & 3 \\
\hline Dry mouth & 2 & 0 & 1 & 0 & 3 \\
\hline Easy Fatigability & 0 & 1 & 0 & 0 & 1 \\
\hline Erectile Dysfunction & 0 & 0 & 1 & 0 & 1 \\
\hline Headache & 2 & 6 & 0 & 0 & 8 \\
\hline Hyperacusis & 1 & 0 & 0 & 0 & 1 \\
\hline Muscle pain & 0 & 0 & 0 & 1 & 1 \\
\hline Nape Pains & 1 & 0 & 0 & 0 & 1 \\
\hline Nausea & 1 & 0 & 0 & 0 & 1 \\
\hline Palpitations & 0 & 1 & 0 & 1 & 2 \\
\hline Temporal headache & 0 & 1 & 0 & 0 & 1 \\
\hline Tingling sensation & 0 & 1 & 0 & 0 & 1 \\
\hline Not specified & 2 & 8 & 1 & 3 & 14 \\
\hline Total & $\mathbf{1 4}$ & $\mathbf{2 1}$ & $\mathbf{3}$ & $\mathbf{6}$ & $\mathbf{4 4}$ \\
\hline
\end{tabular}

population and in the per protocol population. All of the AEs were considered mild to moderate and the most commonly reported event was headache. These findings are consistent with the study of Lewin et al which described headache as the predominant AE reported, adding that the incidence of headache was similar when compared to placebo. The occurrence of headache may be due to vasodilatation which is related to the activation of the L-arginine-nitric oxide system, which in turn, is mediated primarily through the l-isomer [1].

Other adverse events that were observed were difficulty of breathing, dry mouth, bradycardia, chest pains and dizziness, all of which were considered typical of $\beta$-blocker treatment and only had an incidence of about $0.2 \%$. Compared with other $\beta$-blockers, the incidence of AEs observed during nebivolol treatment was still seen to be lower [45]. In 
Collado FR (2018) An open label, multi-center, non-interventional study of the safety of Nebivolol (Nebilet) in the treatment of hypertension in Filipino adult patients: A post marketing surveillance study

Table 13. Number of AEs by causal relation to drug

\begin{tabular}{|c|c|c|c|c|c|c|c|}
\hline \multirow[b]{2}{*}{ Adverse event } & \multicolumn{7}{|c|}{ Causal relation to drug } \\
\hline & Definite & Probable & Possible & Unknown & $\begin{array}{c}\text { Not } \\
\text { related }\end{array}$ & $\begin{array}{l}\text { Missing } \\
\text { answer }\end{array}$ & Total \\
\hline Bradycardia & 0 & 0 & 2 & 0 & 0 & 0 & 2 \\
\hline Chest Pains & 0 & 0 & 2 & 0 & 0 & 0 & 2 \\
\hline Dizziness & 0 & 2 & 0 & 0 & 0 & 0 & 2 \\
\hline DOB & 0 & 1 & 1 & 0 & 0 & 1 & 3 \\
\hline Dry mouth & 0 & 0 & 2 & 1 & 0 & 0 & 3 \\
\hline Easy Fatigability & 0 & 0 & 0 & 0 & 0 & 1 & 1 \\
\hline Erectile Dysfunction & 0 & 0 & 1 & 0 & 0 & 0 & 1 \\
\hline Headache & 3 & 1 & 2 & 1 & 1 & 0 & 8 \\
\hline Hyperacusis & 0 & 0 & 0 & 1 & 0 & 0 & 1 \\
\hline Muscle pain & 0 & 0 & 0 & 0 & 0 & 1 & 1 \\
\hline Nape Pains & 0 & 0 & 0 & 0 & 1 & 0 & 1 \\
\hline Nausea & 0 & 0 & 0 & 0 & 1 & 0 & 1 \\
\hline Palpitations & 0 & 0 & 0 & 1 & 0 & 1 & 2 \\
\hline Temporal headache & 0 & 0 & 0 & 0 & 1 & 0 & 1 \\
\hline Tingling sensation & 0 & 1 & 0 & 0 & 0 & 0 & 1 \\
\hline Not specified & 0 & 2 & 0 & 1 & 0 & 11 & 14 \\
\hline Total & 3 & 7 & 10 & 5 & 4 & 15 & 44 \\
\hline
\end{tabular}

Mean Reduction in SBP ( $\mathrm{mmHg})$

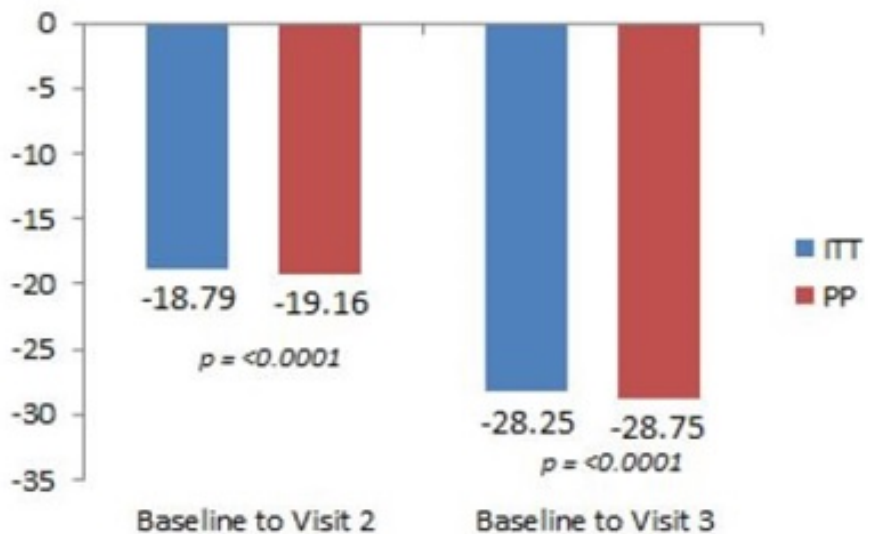

Figure 1. Mean reduction in systolic blood pressure SBP $(\mathrm{mmHg})$ after treatment (ITTIntention to treat, $P P$ - Per population)

\section{Mean Reduction in DBP $(\mathrm{mmHg})$}

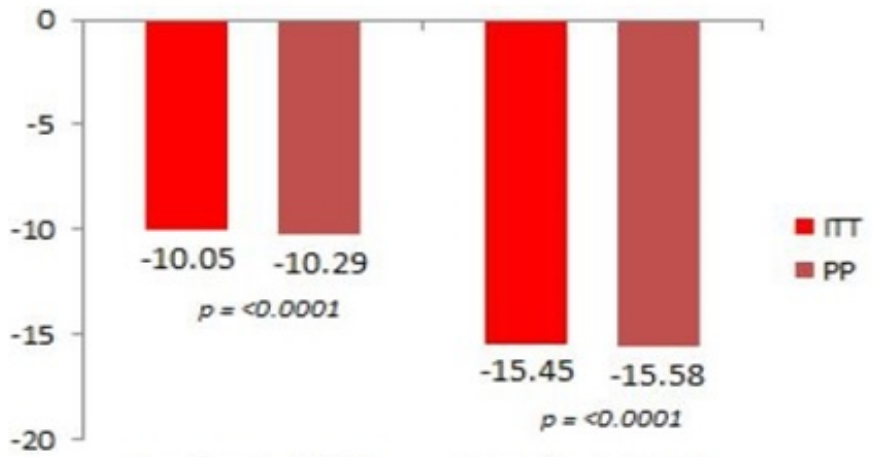

Baseline to Visit $2 \quad$ Baseline to Visit 3

Figure 2. Mean reduction in diastolic blood pressure DBP $(\mathrm{mmHg})$ after treatment (ITT Intention to treat, PP-Per population) addition, a trial on elderly heart failure patients showed that nebivolol had a similar adverse event profile compared to placebo except for an increased incidence of bradycardia [46].

Erectile dysfunction is also a common complaint in $\beta$-blocker users, but in this study, the incidence was only $0.09 \%$ with the use of nebivolol. In fact, Doumas et al. observed that nebivolol was found to have improved erectile function in patients who switched from conventional $\beta$-blockers which may be attributed to enhanced NO bioavailability [47].

With regards to its efficacy, nebivolol was found to be effective in lowering blood pressure significantly. After the first visit, $82 \%$ of patients had reportedly achieved target BPs less than $140 / 90 \mathrm{mmHg}$ or $>10 \mathrm{mmHg}$ decrease in DBP. At the end of the treatment period, almost $97 \%$ of patients had a sustained reduction in both SBP and DBP. Bayar et al. [48] has previously mentioned that in contrast with most $\beta$-adrenoreceptor blockers, nebivolol has vasodilatory properties that are dependent on the presence of the endothelium and are associated with activation of endothelial nitric oxide synthase. There is evidence that nebivolol, in addition to its $\beta 1$-adrenoreceptor blocking effects, can stimulate endothelial NO production, which has been suggested to be mediated, at least in part, by a $\beta 3$-agonistic effect. As a result, there is reduced peripheral resistance, increased stroke volume and preserved cardiac output leading to a decrease in blood pressure [6].

\section{Conclusion}

In conclusion, this post-marketing observational study demonstrates that nebivolol is a safe and effective beta-blocker for the treatment of hypertension. The adverse events reported were consistent with the adverse event profile seen in previous clinical trials and had no significant effect on the outcome of treatment. Its cardioselective and unique vasodilating effects through nitric oxide stimulation makes it an ideal drug for the treatment of essential hypertension. In this realworld study, the use of nebivolol resulted in sustained decrease in both systolic and diastolic blood pressures, reinforcing its clinical usefulness in the maintenance of BP control. 
Collado FR (2018) An open label, multi-center, non-interventional study of the safety of Nebivolol (Nebilet) in the treatment of hypertension in Filipino adult patients: A post marketing surveillance study

Table 14. Line Listing Of Adverse Events

\begin{tabular}{|c|c|c|c|c|c|c|c|c|c|c|}
\hline Obs & $\begin{array}{l}\text { Control } \\
\text { Number }\end{array}$ & Adverse Event & Date of Onset & $\begin{array}{c}\text { Date of } \\
\text { Resolution }\end{array}$ & Severity & Treatment & Other & $\begin{array}{l}\text { If yes, Other } \\
\text { Treatment }\end{array}$ & Outcome & $\begin{array}{l}\text { Causal } \\
\text { Relation } \\
\text { to Drug }\end{array}$ \\
\hline 1 & 0237 & Bradycardia & 14MAY2014 & 15MAY2014 & Mild & Stopped & Yes & $\begin{array}{c}\text { Alzor CCB } \\
\text { 20/5mg/tablet } \\
\text { OD Eltroxin } \\
150 \mathrm{mg} / \text { tablet } \\
\text { OD }\end{array}$ & Disappeared & Possible \\
\hline 2 & 0526 & Palpitation & 23APR2014 & 25APR2014 & Moderate & Stopped & & & Improved & Unknown \\
\hline 3 & 0531 & Dizziness & 30JUN2014 & & Moderate & Stopped & Yes & $\begin{array}{l}\text { LOSARTAN } \\
50 \mathrm{mg} \text { OD }\end{array}$ & Disappeared & Probable \\
\hline 4 & 0701 & $\begin{array}{c}\text { Erectile } \\
\text { Dysfunction }\end{array}$ & 01JUL2014 & & Mild & Continued & No & & Unchanged & Possible \\
\hline 5 & 0710 & Bradycardia & 17SEP2014 & & Mild & Continued & No & & & Possible \\
\hline 6 & 0901 & Dizziness & 01MAY2014 & 03MAY2014 & Moderate & Continued & No & & Disappeared & Probable \\
\hline 7 & 1292 & Headache & 06JUN2014 & 20JUN2014 & Moderate & Continued & Yes & & Improved & Definite \\
\hline 8 & 1298 & Headache & 19JUN2014 & 23JUN2014 & Mild & Continued & No & & Improved & Definite \\
\hline 9 & 1300 & Headache & 29JUN2014 & 13JUL2014 & Mild & Reduced & No & & Improved & Definite \\
\hline 10 & 1333 & & 06JUN2014 & 07JUN2014 & Mild & & Yes & $\begin{array}{l}\text { Omeprazole } \\
\text { Maalox }\end{array}$ & Disappeared & Probable \\
\hline 11 & 1334 & $\begin{array}{l}\text { Hyperacusi } \\
\text { s }\end{array}$ & & & Moderate & Reduced & Yes & & Disappeared & Unknown \\
\hline 12 & 1352 & & 30MAY2014 & & Mild & Stopped & No & & Disappeared & Unknown \\
\hline 13 & 1381 & & 05DEC2014 & & Moderate & Continued & No & & Improved & \\
\hline 14 & 1382 & & 06DEC2014 & & Moderate & Continued & Yes & Pritor & Improved & Probable \\
\hline 15 & 1383 & & 13NOV2014 & & Mild & Continued & Yes & Losartan & Improved & \\
\hline 16 & 1383 & & 04DEC2014 & & Mild & Continued & Yes & Trivase & Unchanged & \\
\hline 17 & 1384 & & 03DEC2014 & & Mild & Continued & Yes & Metoprolol & Improved & \\
\hline 18 & 1385 & & 06SEP2014 & & Mild & Continued & Yes & $\begin{array}{l}\text { Trivase } \\
\text { Dologesic }\end{array}$ & Improved & \\
\hline 19 & 1386 & & 05DEC2014 & & Moderate & Continued & Yes & $\begin{array}{l}\text { Pritor, Trivase, Imdur, } \\
\text { Zerodol }\end{array}$ & & \\
\hline 20 & 1387 & & 05DEC2014 & & Mild & Continued & Yes & Amlodipine & & \\
\hline 21 & 1388 & & 25JUN2014 & & Moderate & Reduced & Yes & Candez & Improved & \\
\hline 22 & 1388 & & 15SEP2014 & & Moderate & Continued & Yes & Exforge & Improved & \\
\hline 23 & 1389 & & 09DEC2014 & & Mild & Continued & Yes & $\begin{array}{l}\text { Lanoxin } \\
\text { Aldactone }\end{array}$ & Improved & \\
\hline 24 & 1390 & & 09DEC2014 & & Mild & Continued & Yes & Relaxid & & \\
\hline 25 & 2101 & Dry mouth & & & Moderate & Continued & No & & Unchanged & Possible \\
\hline 26 & 2102 & DOB & & & Mild & Reduced & No & & Improved & Probable \\
\hline 27 & 2102 & Headache & & & Mild & Reduced & No & & Improved & Probable \\
\hline 28 & 2103 & $\begin{array}{l}\text { Chest } \\
\text { Pains }\end{array}$ & & & Moderate & Reduced & No & & Improved & Possible \\
\hline 29 & 2103 & DOB & & & Mild & Reduced & No & & Improved & Possible \\
\hline 30 & 2104 & Easy fatigability & & & Moderate & Continued & No & & Improved & \\
\hline 31 & 2105 & Headache & & & Mild & Continued & No & & Disappeared & Not related \\
\hline 32 & 2106 & Palpitations & & & Mild & Continued & No & & & \\
\hline 33 & 2107 & Headache & & & Moderate & Reduced & No & & Improved & Possible \\
\hline 34 & 2108 & Chest Pains & & & Moderate & Reduced & No & & Disappeared & Possible \\
\hline 35 & 2109 & DOB & & & Moderate & Continued & Yes & & Disappeared & \\
\hline 36 & 2109 & Dry Mouth & & & Moderate & Continued & No & & Disappeared & Unknown \\
\hline 37 & 2110 & Dry Mouth & & & Moderate & Continued & No & & Disappeared & Possible \\
\hline 38 & 2110 & Headache & & & Mild & Continued & No & & Disappeared & Unknown \\
\hline 39 & 2110 & Nape Pains & & & Mild & Continued & No & & Disappeared & Not related \\
\hline 40 & 2123 & $\begin{array}{l}\text { Temporal } \\
\text { headache }\end{array}$ & 15MAY2014 & & Mild & Continued & & & Improved & Not related \\
\hline 41 & 2126 & Headache & 12MAY2014 & & Mild & Continued & No & & Improved & Possible \\
\hline 42 & 2126 & Nausea & 05MAY2014 & & Mild & Continued & No & & Disappeared & Not related \\
\hline 43 & 2130 & Muscle pain & 10MAY2014 & & Moderate & Continued & & & & \\
\hline 44 & 2264 & $\begin{array}{l}\text { Tingling } \\
\text { sensation }\end{array}$ & 06SEP2014 & & Mild & Continued & Yes & OLMESARTAN & Improved & Probable \\
\hline
\end{tabular}

Listed above are the adverse events reported during the treatment period involving 1,154 patients. 


\section{Percentage of Patients with Adverse Events}
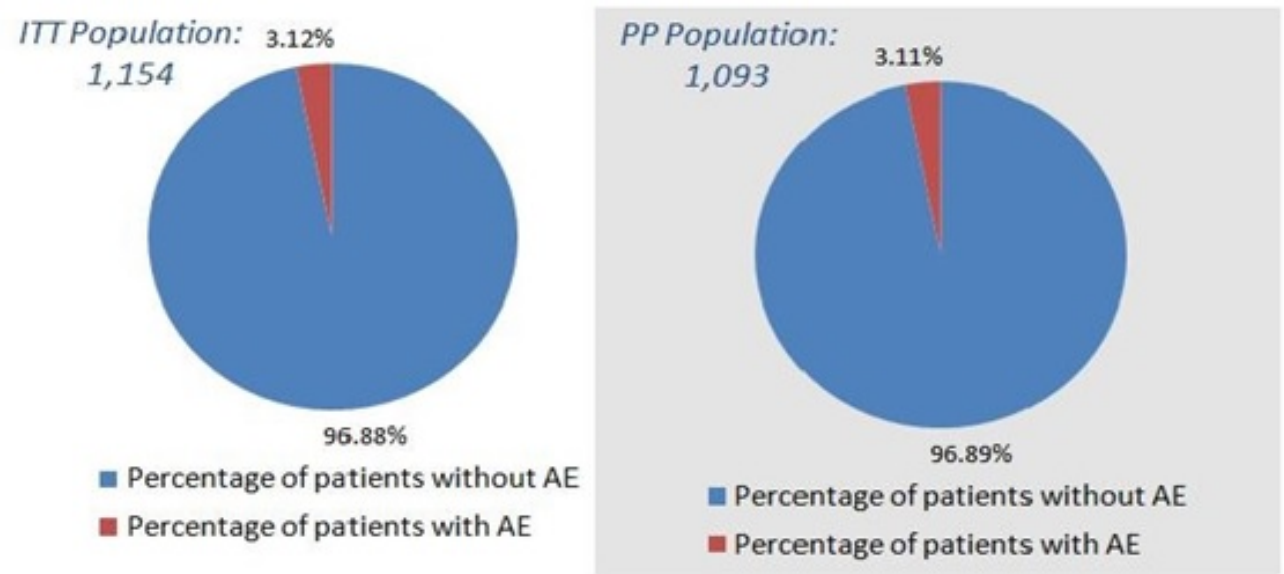

Figure 3. Percentage of patients with adverse events to nebivolol (Nebilet). Only $3 \%$ of patients had adverse events in the intention to treat (ITT) population and in the per protocol (PP) population

\section{Declarations}

Ethical approval and consent to participate: Informed consent was obtained from all individual participants included in the study. All procedures performed in studies involving human participants were in accordance with the ethical standards of the institutional and/or national research committee and with the 1964 Helsinki declaration and its later amendments or comparable ethical standards. The terms of this arrangement have been reviewed and approved by the Institutional Ethics Review Committee of St. Luke's Medical Center, Research and Biotechnology Division, Quezon City, Philippines in accordance with its policy on objectivity in research.

Availability of supporting data: The data that support the findings of this study are available from the corresponding author upon reasonable request.

Competing interests: The author declares that she has no conflicts of interest.

Funding: The author of this publication had research support from A. Menarini Philippines, Inc. (formerly Invida Philippines Inc.).

\section{References}

1. Greathouse M (2010) Nebivolol efficacy and safety in patients with stage I-II hypertension. Clin Cardiol 33: E20-27. [Crossref]

2. De Cree J, Geukens H, Verhaegen H (1991) Non-invasive cardiac haemodynamics of nebivolol. An overview. Drug Invest 3: 40-50.

3. Jennings G, Esler M, Dart A, Dyke A, Lambert G, et al. (1991) Effects of nebivolo on haemodynamic cardiac dimension and function, cardiovascular reflexes and biochemical measures of sympathetic activity in normal subjects. Drug Invest 3: 51-59.

4. Eichstadt H, Kaiser W, Mockel M (1997) Haemodynamic measurements in patients under the $\beta 1$ receptor blocker nebivolol. Perfusion 12: 449-454

5. Brett SE, Forte P, Chowienczyk PJ, Benjamin N, Ritter JM (2002) A comparison of the effects of nebivolol and bisoprolol on systemic vascular resistance in patients with essential hypertension. Clin Drug Invest 22: 355-359.

6. Kamp O, Sieswerda GT, Visser CA (2003) Comparison of effects on systolic and diastolic left ventricular function of nebivolol versus atenolol in patients with uncomplicated essential hypertension. Am J Cardiol 92: 344-348.

7. Kozàkovà M, Palombo C, Pratali L, Pittella G, Galetta F, et al. (1997) Mechanisms of coronary flow reserve impairment in human hypertension. Hypertension 29: 551-559.
8. Kozakowa M, Galetta F, Gregorini L, Bigalli G, Franzoni F, et al. (2000) Coronary vasodilator capacity and epicardial vessel remodelling in physiological and hypertensive hypertrophy. Hypertension 36: 343-349.

9. Palombo C, Kozakova M, Magagna A, Bigalli G, Morizzo C, et al. (2000) Early impairment of coronary flow reserve and increase in minimum coronary resistance in borderline hypertensive patients. J Hypertens 18: 453-459.

10. Rizzoni D, Palombo C, Porteri E, Muiesan ML, Kozàkovà M, et al. (2003) Relationships between coronary flow vasodilator capacity and small artery remodeling in hypertensive patients. J Hypertens 21: 625-631.

11. Kozàkovà M, de Simone G, Morizzo C, Palombo C (2003) Coronary vasodilator capacity and hypertension-induced increase in left ventricular mass. Hypertension 41 224-229.

12. Hamasaki S, Al Suwaidi J, Higano ST, Miyauchi K, Holmes DR Jr, et al. (2000) Attenuated coronary flow reserve and vascular remodelling in patients with hypertension and left ventricular hypertrophy. J Am Coll Cardiol 35: 1654-1660.

13. Galderisi M, Cicala S, Caso P, De Simone L, D’Errico A, et al. (2002) Coronary flow reserve and myocardial diastolic dysfunction in arterial systemic hypertension. $\mathrm{Am} J$ Cardiol 90: 860-864.

14. Galderisi M, Caso P, Cicala S, De Simone L, Barbieri M, et al, (2002) Positive association between circulating free IGF-1 and coronary flow reserve in arterial systemic hypertension. Am J Hypertens 15: 766-772.

15. Galderisi M, de Simone G, Cicala S, De Simone L, D'Errico A, et al. (2003) Coronary flow reserve in hypertensive patients with appropriate or inappropriate left ventricular mass. J Hypertens 21: 2183-2188. [Crossref]

16. Galderisi M, Cicala S, D’Errico A, de Divitiis O, de Simone G (2004) Nebivolol improves coronary flow reserve in hypertensive patients without coronary heart disease. J Hypertens 22: 2201-2208.

17. Liu GS, Wang LY, Nueten LV, Ooms LA, Borgers M, et al. (1999) The effect of nebivolol on left ventricular hypertrophy in hypertension. Cardiovasc Drugs Ther 13 549-551. [Crossref]

18. Guerrero EI, Ardanaz N, Sevilla MA, Arévalo MA, Montero MJ (2006) Cardiovascula effects of nebivolol in spontaneously hypertensive rats persist after treatment withdrawal. J Hypertens 24: 151-158.

19. Schnaper H, Jackson D, Sit SP (1991) Nebivolol a new generation of $\beta$-blockers in hypertension. Am J Hypert 4: 23A.

20. Sieben G, Van Nueten L, Symoens J (1991) Nebivolol in hypertension. Drug Invest 3: 193-195.

21. Van Nueten L, Dupont AG, Vertommen C, Goyvaerts H, Robertson JI (1997) A doseresponse trial of nebivolol in essential hypertension. J Hum Hypertens 11: 139-144. [Crossref] 
Collado FR (2018) An open label, multi-center, non-interventional study of the safety of Nebivolol (Nebilet) in the treatment of hypertension in Filipino adult patients: A post marketing surveillance study

22. Stoschitzky K, Stoschitzky G, Brussee H, Bonelli C, Dobnig H (2006) Comparing beta-blocking effects of bisoprolol, carvedilol and nebivolol. Cardiology 106: 199-206. [Crossref]

23. Robertson JIS (1995) Clinical expert report.

24. Lacourcière Y, Poirier L, Lefebvre J, Provencher P, Arnott W (1992) Comparative effects of a new cardioselective $\beta$-blocker nebivolol and nifedipine sustained-release on 24-hours ambulatory blood pressure and plasma lipoproteins. J Clin Pharmacol 32: 660-666.

25. Lacourcière Y, Lefebvre J, Poirier L, Archambault F, Arnott W (1994) Treatment of ambulatory hypertensives with nebivolol or hydrochlorothiazide alone or in combination. Am J Hypert 7: 137-145.

26. Weiss RJ, Weber MA, Carr AA, Riggs BS (2005) Nebivolol in the treatment of patients with stage 1 and 2 hypertension. Results of a randomized, double-blind, placebocontrolled study. Am J Hypertens 18: 96A.

27. Van Nueten L, Taylor FR, Robertson JI (1998) Nebivolol vs atenolol and placebo in essential hypertension: a double-blind randomised trial. J Hum Hypertens 12: 135-140. [Crossref]

28. Cleophas TJ, Graboowsky I, Niemeyer MG, Makel WN, van der Wall EE, et al. (2001) Long-term efficacy of nebivolol monotherapy in patients with hypertension. Curr Therap Res 62: 451-461.

29. Cleophas TJ, Agrawal R, Lichtenthal A, Mäkel W, Fici F (2006) Nationwide efficacysafety study of nebivolol in mildly hypertensive patients. Am J Therap 13: 192-197.

30. Pesant Y, Marc-Aurèle J, Bielmann P, Alaupovic P, Cartier P, et al. (1999) Metabolic and antihypertensive effects of nebivolol and atenolol in normometabolic patients with mild-moderate hypertension. Am J Therap 6: 137-147.

31. Grassi G, Trevano FQ, Facchini A, Toutouzas T, Chanu B, et al. (2003) Efficacy and tolerability profile of nebivolol vs atenolol in mild-moderate essential hypertension: results of a double-blind randomized multicentre trial. Blood Press 2: 35-40.

32. Uhlir O, Fejfusa M, Havranek K, Lefflerová K, Vojáček J, et al. (1991) Nebivolol versus metoprolol in the treatment of hypertension. Drug Invest 3: 107-110.

33. Czuriga I, Riecansky I, Bodnar J, Fulop T, Kruzsicz V, et al. (2003) Comparison of the new cardioselective beta-blocker nebivolol with bisoprolol in hypertension: the Nebivolol, Bisoprolol Multicenter Study (NEBIS). Cardiovasc Drugs Ther 17: 257-263.

34. Mazza A, Gil-Extremera B, Maldonato A, Toutouzas T, Pessina AC (2002) Nebivolol vs amlodipine as first-line treatment of essential arterial hypertension in the elderly. Blood Pressure 11: 182-188.

35. Van Nueten L, Lacourcière Y, Vyssoulis G, Korlipara K, Marcadet DM, et al. (1998) Nebivolol versus nifedipine in the treatment of essential hypertension: a double blind, randomized, comparative trial. Am J Therap 5: 237-243.
36. Rosei EA, Rizzoni D, Comini S (2003) Evaluation of the efficacy and tolerability of nebivolol versus lisinopril in the treatment of essential arterial hypertension: a randomized, multicenter, double-blind study. Blood Pressure 12: 30-35.

37. Van Nueten L, Schelling A, Vertommen C, Dupont AG, Robertson JI (1997) Nebivolol vs enalapril in the treatment of essential hypertension: a double-blind randomised trial. J Hum Hypertens 11: 813-819. [Crossref]

38. Van Bortel LM, Bulpitt CJ, Fici F (2005) Quality of life and antihypertensive effect with nebivolol and losartan. Am J Hypertens 18: 1060-1066. [Crossref]

39. Van Nueten L, Taylor FR, Robertson JIS (1998) Nebivolol vs atenolol and placebo in essential hypertension: a double-blind randomized trial. J Hum Hypertens 12: 135-140.

40. Simon G, Johnson ML (1993) Comparison of antihypertensive and $\beta 1$-adrenoceptor antagonist effect of nebivolol and atenolol in essential hypertension. Clin Exper Hypert 15: 501-509.

41. Van Neuten L, van Grieken M, Dom J (1994) Nebivolol versus nifedipine LA in the treatment of hypertension.15th Scientific Meeting of the International Society of Hypertension, Melbourne. J Hypert 20: 03

42. Van Bortel L (2007) Beta-blockers are not all equal: a meta-analysis of the efficacy and tolerability of nebivolol versus other antihypertensive drugs. In Press.

43. Van Nueten L, Rishøj Nielsen M, Vertommen C, Dupont AG, Robertson JI (1999) Nebivolol versus enalapril in essential hypertension: long term double-blind comparative trial. Acta Clinica Belgica 54: 19-25.

44. Giles TD, Khan BV, Lato J, Brener L, Ma Y, et al. (2013) Nebivolol monotherapy in younger adults (younger than 55 years) with hypertension: a randomized, placebocontrolled trial. J Clin Hypertens 15: 687-693.

45. Ambrosioni E, Borghi C (2005) Tolerability of nebivolol in head-to-head clinical trials versus other cardioselective B-blockers in the treatment of hypertension. High Blood Press Cardiovasc Prev 12: 27-35.

46. Flather MD, Shibata MC, Coats AJ, Van Veldhuisen DJ, Parkhomenko A, et al. (2005) Randomized trial to determine the effect of nebivolol on mortality and cardiovascular hospital admission in elderly patients with heart failure (SENIORS). Eur Heart $J$ 26: 215-225

47. Doumas M, Tsakiris A, Douma S, Grigorakis A, Papadopoulos A, et al. (2006) Beneficial effects of switching from beta-blockers to nebivolol on the erectile function of hypertensive patients. Asian J Androl 8: 177-182.

48. Bayar E, Ilhan G, Furat C, Atik C, Arslanoglu Y, et al. (2014) The effect of different $\beta$-blockers on vascular graft nitric oxide levels: comparison of nebivolol versus metoprolol. Eur J Vasc Endovasc Surg 47: 204-208.

Copyright: (C2018 Collado FR. This is an open-access article distributed under the terms of the Creative Commons Attribution License, which permits unrestricted use, distribution, and reproduction in any medium, provided the original author and source are credited. 